\title{
Fate and Immunotoxic Effects of Silver Nanoparticles on Rainbow Trout in Natural Waters
}

\author{
Bruneau $\mathrm{A}^{1,2^{\star}}$, Turcotte $\mathrm{P}^{2}$, Pilote $\mathrm{M}^{2}$, Gagné $\mathrm{F}^{1}$ and Gagnon $\mathrm{C}^{2 *}$ \\ ${ }^{1}$ Emerging Methods Section, Environment Canada, 105 McGill Street, Montreal, Quebec, Canada H2Y 2E7 \\ ${ }^{2}$ Wastewater and Effluents Section, Environment Canada, 105 McGill Street, Montreal, Quebec, Canada H2Y 2E7
}

\begin{abstract}
This study investigates the fate and the effects of silver nanoparticles (AgNPs) in rainbow trout (Oncorhynchus mykiss). Juveniles were exposed to $50 \mu \mathrm{g} / \mathrm{L}$ of AgNPs $20 \mathrm{~nm}$ and $1 \mu \mathrm{g} / \mathrm{L}$ of dissolved silver $\mathrm{Ag}^{+}\left(\mathrm{as} \mathrm{AgNO}_{3}\right)$ in three types of water differing in conductivity, $\mathrm{pH}$ and organic matter: green water (Saint-Lawrence River), brown water (Ottawa River), and UV-treated and dechlorinated tap water. After a $96 \mathrm{~h}$ exposure, chemical analyses were performed on both water samples and fish tissues (liver and gills) and a suite of immune and hepatic biomarkers were also performed on fish. Results demonstrated that brown water with high organic carbon values $(7 \mathrm{mg} / \mathrm{L})$, promoted the formation of small AgNP aggregates that were bioaccumulated in fish gills and liver. In fish exposed to AgNPs, immunostimulation and hepatic oxidative stress were observed in pronephros and liver respectively. Dissolved $\mathrm{Ag}^{+}$in brown water was associated to small colloids, promoted silver bioavailability and induced leucocytes immunostimulation. The higher alkalinity and conductivity of green water promoted morphological AgNPs transformations. Although, AgNPs neither induced immune nor hepatic damages, $\mathrm{AgNO}_{3}$ induced leucocyte stimulation and a hepatic pro-inflammatory response. $\mathrm{Ag}$ from AgNPs and $\mathrm{AgNO}_{3}$ was bioaccumulated in gills, and liver without hepatic injury (oxidative stress). $\mathrm{AgNO}_{3}$ induced immunosuppression and oxidative stress in pronephros. This study shows that water parameters influence the fate, bioavailability and the toxicity AgNPs and dissolved $\mathrm{Ag}^{+}$in fish. Brown water showed more harmful effects with AgNPs than tap and green waters.
\end{abstract}

Keywords: Nanotoxicity; Rainbow trout; Immunotoxicity; Natural waters

\section{Introduction}

The large and increasing use of silver nanoparticles (AgNPs) represents an emerging environmental issue. Indeed, they are widely used in many domains, mainly in medicine and textiles from which they are released in the environment. AgNPs are employed for their antimicrobial and biocidal properties [1-3]. Silver is well-known for its toxic properties to organisms. In the last decade, an increasing number of studies have focused on AgNP toxicity. For example, fish exposed to silver NPs led to embryonic deformation and lethality, inflammatory effects, dampened mitochondrial activity, oxidative stress mechanism, cytotoxicity, and apoptosis [4-8]. AgNPs change gene expression in the rainbow trout liver with the increase of gene expression in genes involved in oxidative stress (lipid peroxidation, oxidized metallothioneins), and the immune function [9]. However the behavior, bioavailability and toxicity of AgNPs in various types of freshwater are less understood at the present time. The surface water characteristics such as alkalinity, $\mathrm{pH}$, conductivity and dissolved organic matter could have major influence towards aquatic biota $[10,11]$.

Particle surface charges (Zeta potential) and the composition of surface water could change the size distribution of nanoparticles [12]. The presence of bacteria, alkalinity, natural organic matter (NOM) concentrations and charges may induce aggregation depending of nanoparticle's surface properties, and influence the transport of nanoparticles in aquatic environments [13]. Nanoparticles tend to form aggregates in solution depending on the presence of salts and natural organic matter (NOM) and the intrinsic Zeta potential of the nanoparticle. On one hand, a nanoparticle with a low surface charge tends to aggregate in media with low salt concentrations. On another hand, the NOM could increase the nanoparticle polarity (and surface charge) and promote the NP monomeric form [13].

In order to maintain a non-aggregated state, nanoparticles were charge stabilized in industry. A surface's charge stabilized nanoparticles present counter ions and solvent molecule at their surface (Stern layer). A modification in the ionic concentrations of the media could alter the stability of the nanoparticle and induce aggregation or precipitation [14]. NPs with low Zeta potential tend to aggregate more quickly than those with higher zeta potential. The Zeta potential of citrate coated AgNPs $20 \mathrm{~nm}$ is $-50 \mathrm{~m}$ Volt which is considered relatively low and modification of the charge surface potential in contact with a natural media could change the dispersion of AgNPs. AgNPs could also liberate silver ions in water which involves the loss of electron, resulting in an oxidative process [15]. A partial oxidation of AgNPs could occur in oxidant media with oxygen species [16]. This oxidation process influences the liberation of the Ag+ from the AgNPs and could change the original properties of the nanoparticles (size, shape, and functionalization) [17]. In natural media (surface water), the $\mathrm{Ag}^{+}$form was retrieved as monovalent ions $\left(\mathrm{Ag}^{+}\right)$was complexed when adsorbed into particulate matter with sulfide, bicarbonate or sulfate [18-20]. Liu et al., showed that the release rate of $\mathrm{Ag}^{+}$ions from $\mathrm{AgNPs}$ was blocked by the presence of NOM, by the binding to negatively charged ligands, such as $\mathrm{S}^{2-}, \mathrm{SO}_{4}{ }^{2-}, \mathrm{CO}_{3}{ }^{2-}$ and $\mathrm{Cl}^{-}, \mathrm{NH}_{3}^{-}$low temperatures and alkaline $\mathrm{pH}$ [10]. Hence, the properties of different receiving waters could have a profound influence on the fate of NPs in the environment. For example, aggregated NPs will tend to associate with suspended matter

*Corresponding author: Christian Gagnon, Waste water and Effluents Section, Environment Canada, 105 McGill Street, Montreal, Quebec, Canada H2Y 2E7, Tel: 514-496-7096; E-mail: christian.gagnon@ec.gc.ca

Received March 29, 2015; Accepted April 24, 2015; Published May 10, 2015

Citation: Bruneau A, Turcotte P, Pilote M, Gagné F, Gagnon C (2015) Fate and Immunotoxic Effects of Silver Nanoparticles on Rainbow Trout in Natural Waters. J Nanomed Nanotechnol 6: 290. doi:10.4172/2157-7439.1000290

Copyright: (c) 2015 Bruneau A, et al. This is an open-access article distributed under the terms of the Creative Commons Attribution License, which permits unrestricted use, distribution, and reproduction in any medium, provided the original author and source are credited. 
and sediments which, in turn, influence the exposure pathway in fish or other aquatic organisms.

In this study 3 types of surface waters were selected for their specific characteristics: brown water was chosen for the high total organic carbon (TOC) concentrations which can neutralise the surface charge of the AgNPs and conserve their monomeric form. The green water with algae suspensions from St. Lawrence River has an alkaline $\mathrm{pH}(\mathrm{pH}$ 7.8-8.5) that could favour AgNPs degradation. Finally, tap water with low natural organic matter concentrations and high conductivity (high dissolved ionic species) could modify the original properties of the AgNPs and promote their bioavailability for the aquatic species.

Nanoparticles are thought to enter the organism by two fundamental pathways. The first concerns the interaction through gills were nanoparticles and other particles could adsorb to the surface of gills and enter the circulatory system. The liberation of free metal (Ag in the present study) could also be transferred from the nanoparticles and gill membranes. The second process involves the gut epithelium, NPs could enter in the organism though the gut mucosa via endocytosis, circulate in blood vessels and reach internal organs [21,22].

In macrophages NPs could be internalised via pinocytosis phenomenon, phagocytosis and receptor mediated endocytosis [23]. NPs could also be assimilated with cell membrane association process and release free metal ions [24] and degraded in phagolysosomes with the action of hydrolytic enzymes. AgNPs were recognized to directly impact the immune system [25] and the toxicity cannot be entirely explained by $\mathrm{Ag}^{+}$ions release [26]. To prevent the oxidative stress caused by $\mathrm{Ag}^{+}$, defences mechanism were engaged like anti-oxidant proteins such as cysteine rich proteins like glutathione and thiols [27]. Moreover the oxidative damages could be followed by the determination of lipid peroxidation and the cyclooxygenase measures.

The purpose of this study was to measure the effect of three types of natural water on the size distribution of $\mathrm{AgNPs}$ and $\mathrm{AgNO}_{3}$, their bioavailability for fish gills and liver and their immunotoxicological and hepatic effects. $\mathrm{Ag}^{+}$(as $\mathrm{AgNO}_{3}$ ) is recognized as a high toxic silver species to aquatic organism with a lethal concentration $50 \%$ for rainbow trout of $9.1 \mu \mathrm{g} / \mathrm{L}$ after $168 \mathrm{~h}$ [28]. In our study, we exposed fish to a sublethal concentration of $\mathrm{Ag}^{+}$that correspond to the potentially released $\mathrm{Ag}^{+}$fraction (2\%) from AgNPs. According to Liu et al., [24] 1\% of silver from AgNPs was solubilized in the water after 1 hour at $\mathrm{pH}=6$.

\section{Materials and Methods}

\section{Silver nanoparticle}

A stock solution of Silver Nanoparticles (AgNPs) from Ted Pella Inc (PELCO ${ }^{\circ} \mathrm{NanoXact}^{\mathrm{in}}$, California, USA) was used. The AgNP suspension has a light brown colour and consists of a silver shell core capped with citrate. According to the manufacturer's specifications, the AgNPs have a mean size of $22 \pm 2 \mathrm{~nm}$, at a density of $4.5 \times 10^{11}$ particles $/ \mathrm{mL}$ in 2 $\mathrm{mM}$ citrate buffer, with $\mathrm{pH} 7.4$ and a zeta potential at $-50 \mathrm{mV}$ (silver concentration $=0.02 \mathrm{mg} / \mathrm{ml}$ ). For the exposure media, a concentration of $50 \mu \mathrm{g} / \mathrm{L}$ was dispersed directly in the fish tank.

\section{Fish}

Juvenile rainbow trout (Oncorhynchus mykiss) (mean size $117 \mathrm{~mm}$ $\pm 28 \mathrm{~mm}$; mean weight $23 \mathrm{~g} \pm 7 \mathrm{~g}$ ) were provided by a local hatchery (Pisciculture des Arpents-Vert, Ste-Edwidge, Qc). Fish were maintained in 1000-L tanks of UV treated and charcoal activated filtered water at $15^{\circ} \mathrm{C}$, fed one time a day with a commercial trout chow during 2 weeks for acclimation. Throughout the acclimation and the exposure periods, the rainbow trout were held under a natural photoperiod $(12 \mathrm{~h}$ light: $12 \mathrm{~h}$ dark).

\section{Types of water}

Two types of surface water were sampled from the St. Lawrence and Ottawa River called green and brown water, respectively. Waters were chosen according to their own properties and their differences (Table 1). The green water has an alkaline $\mathrm{pH}$ (7.7) and moderate total organic carbon (TOC) $(3.2 \mathrm{mg} / \mathrm{L})$ and high conductivity $(218 \mu \mathrm{S} / \mathrm{cm})$. Brown water has an acidic $\mathrm{pH}(6.7)$, high TOC $(7 \mathrm{mg} / \mathrm{L})$ and low conductivity $(63 \mu \mathrm{S} / \mathrm{cm})$ (Table 1). The tap water originating from the St. Lawrence River was treated by UV treatment and charcoal activated filtration has high conductivity $(284 \mu \mathrm{S} / \mathrm{cm})$ and low TOC $(1.9 \mathrm{mg} / \mathrm{L})$.

\section{Fish exposure}

Fish (N=8 fish per exposure container) were placed in $20 \mathrm{~L}$ containers lined with polyethylene bags and exposed for $96 \mathrm{~h}$ at $15^{\circ} \mathrm{C}$ to each type of water spiked with either silver nanoparticles (AgNPs) $(50$ $\mu \mathrm{g} / \mathrm{L})$ or dissolved silver $\left(\mathrm{AgNO}_{3}\right)(1 \mu \mathrm{g} / \mathrm{L})$. The control group consisted of fish exposed to aquarium water (dechlorinated and UV-treated tap water of the City of Montreal). The exposure experiment was repeated twice. The fish were monitored daily for any signs of distress or changes in behaviour. Water quality parameters (dissolved oxygen, $\mathrm{pH}$ and temperature) were monitored daily. Dissolved oxygen was maintained above $80 \%, \mathrm{pH}$ between $6.7-8.8$, and temperature at $15^{\circ} \mathrm{C}$. After the exposure period, the fish were ethically euthanized with $0.1 \%$ of MS222 (Sigma-Aldrich, ON, Canada). Pronephros was kept for immune parameter measures. Liver and gills were immediately collected, weighed and stored at $-80^{\circ} \mathrm{C}$ for subsequent chemical and biochemical analyses.

\section{AgNP characterization in surface waters}

Transmission Electron Microscope (TEM) observation and Energy Dispersive Spectra (EDS): After the end of exposure, AgNPs in each type of water were collected and kept at $4^{\circ} \mathrm{C}$ and were observed by TEM. The stock suspension of AgNPs was also observed by TEM. A drop of each exposure medium containing AgNPs was placed on a copper grid capped with a lacey carbon film for TEM analysis. Once the sample was dehydrated for a few minutes, it was analysed by TEM (JEOL, 2100-F model) operated at $200 \mathrm{kV}$ for image capture in clear bottom. For each TEM picture, an electron-dispersive x-ray analysis (EDS) was performed for element composition of targeted particles.

Dynamic light scattering: Nanoparticle hydrodynamic size and Zeta potential were measured using dynamic light scattering (DLS) (BrookHaven Instrument Corp., ZetaPlus/Bl-PALS) in a stock solution and exposure media. Each water sample was previously filtered on a 450 nm membrane prior measurements to remove large colloids (Filtropur, Sarstedt, QC, Canada). The AgNP stock solution was also diluted 1/10 with distilled water before the measurement on the DLS.

Filtration and ultrafiltration: AgNPs were characterized for their

\begin{tabular}{|c|c|c|c|c|c|}
\hline Water & $\begin{array}{c}\text { Localisation } \\
\text { (North) }\end{array}$ & Localisation (West) & $\begin{array}{c}\text { TOC } \\
(\mathbf{m g} / \mathbf{L})\end{array}$ & $\mathbf{p H}$ & $\begin{array}{c}\text { Conductivity } \\
(\boldsymbol{\mu S} / \mathbf{c m})\end{array}$ \\
\hline Tap & $45,500437^{\circ} \mathrm{N}$ & $73,555977^{\circ} \mathrm{W}$ & 1.9 & 7.9 & 284 \\
\hline Green & $45,66063^{\circ} \mathrm{N}$ & $73,47092^{\circ} \mathrm{W}$ & 3.2 & 7.7 & 218 \\
\hline Brown & $45,56769^{\circ} \mathrm{N}$ & $74,37961^{\circ} \mathrm{W}$ & 7.0 & 6.7 & 63 \\
\hline
\end{tabular}

Table 1: Sampled sites for water exposure, for each sample at least 60 liters were sampled in November 2012. 
size distribution by a procedure described in Bruneau et al., [29]. Briefly, the AgNPs were fractionated by microfiltration and ultrafiltration membranes (regenerated cellulose membranes: Millipore, Canada) using a decreasing porosity size gradient. A subsample of $250 \mathrm{~mL}$ of AgNP suspension in each type of water was first filtered on a membrane of $450 \mathrm{~nm}$ porosity (FHLC04700, Millipore) and $50 \mathrm{~mL}$ were then sampled for total Ag determination. The $450 \mathrm{~nm}$ filtrate was passed through membranes of two different pore sizes: $100 \mathrm{~nm}$ (VCTP04700, Millipore) and $50 \mathrm{~nm}$ (VMWP04700, Millipore).

An ultrafiltration cell with constant agitation was used (Amicon 400 system, Millipore) for the ultrafiltration with $1 \mathrm{kDa}$ cut-off (YM1 $76 \mathrm{~mm}$ diameter, $1.5 \mathrm{~nm}$ filter size). The pressure in the system was maintained constant at $62 \mathrm{psi}, 20^{\circ} \mathrm{C}, 29 \mathrm{~min} \pm 6 \mathrm{~min}$. This ultrafiltration step was considered to provide the "truly" dissolved fraction. Mean total concentrations of $\mathrm{Ag}$ were determined for the filtered, permeate and retentate fractions (XSERIES 2 ICP-MS, Thermo Scientific, USA). The detection limit for silver is of $10 \mathrm{ng} / \mathrm{L}$. Exposure concentrations were expressed as total silver in $\mu \mathrm{g} / \mathrm{L}$ that was measured in the exposure tanks in triplicate.

\section{Silver bioaccumulation}

To determine the effect of water types on silver bioaccumulation, livers and gills of rainbow trout were sampled and weighed and frozen at $-80^{\circ} \mathrm{C}$ until analysis. Tissues were acid-digested with $8 \mathrm{ml}$ of concentrated $\mathrm{HNO}_{3}, 1 \mathrm{ml}$ of concentrated $\mathrm{HCl}$, and $2 \mathrm{ml}$ of concentrated $\mathrm{H}_{2} \mathrm{O}_{2}$. The tissues were then digested during $2 \mathrm{~h}$ at $170^{\circ} \mathrm{C}$ using a microwave digestion system (Ethos EZ, Milestone Scientific ${ }^{\text {Inc }}$, ON, Canada). The samples were completed to final volume of $12 \mathrm{ml}$ with deionized water. Total silver concentration was afterwards determined by XSERIES 2 ICP-MS (Thermo Scientific, USA) with a detection limit of $10 \mathrm{ng} / \mathrm{L}$

\section{Immune parameters}

To determine the impact of AgNPs and $\mathrm{AgNO}_{3}$ on the fish immune system, pronephros was removed under sterile conditions (laminar flow hood) Pronephros was homogenised with sterile stainless steel mesh (100 mm diameter) in tissue culture medium RPMI 1640 (SigmaAldrich, ON, Canada) supplemented with $10 \mathrm{U} / \mathrm{mL}$ heparin (CDMV, QC, Canada), $10 \mathrm{mM}$ HEPES (Sigma-Aldrich, ON, Canada), penicillin $(100 \mathrm{U} / \mathrm{mL})$, streptomycin $(100 \mu \mathrm{g} / \mathrm{mL})$, and $10 \%$ heat-inactivated Fotal Bovine Serum (FBS) at pH 7.4. The leucocytes extracted from the pronephros were then collected by centrifugation of a 51\% Percoll gradient at $400 \mathrm{~g}, 30 \mathrm{~min}, 20^{\circ} \mathrm{C}$ (Sigma-Aldrich, ON, Canada). Cells were collected from the gradient interface and washed twice in PBS (Sigma-Aldrich, ON, Canada) and resuspended in RPMI without heparin but containing 10\% FBS, $100 \mathrm{U} / \mathrm{mL}$ penicillin, $100 \mu \mathrm{g} / \mathrm{mL}$ streptomycin and $10 \mathrm{mM}$ HEPES for phagocytosis, viability, and ROS analyses. The ratio of live to dead cells was assessed using Trypan blue dye exclusion under a microscope with a haemocytometer and it exceeded $90 \%$.

Viability: Cell viability was determined by the dye exclusion assay using $2 \mu \mathrm{g} / \mathrm{ml}$ of propidium iodide dye and flow cytometry (Guava Easycyte, Millipore, USA).One $\mathrm{mL}$ of adjusted cell concentration ( 2 million/ml) was added to 24 -well plates tissue culture treated in duplicate. The cells were incubated in dark lightover $18 \mathrm{~h}$ at $15^{\circ} \mathrm{C}$. Following the incubation, the cells were centrifuged for $5 \mathrm{~min}$ at 250 $\mathrm{g}$, and they were resuspended in a Versen solution ( $0.2 \%$ of EDTA), and blocked with a ratio v:v with Roswell Park Media Institute (RPMI) containing $10 \% \mathrm{FBS}, 100 \mathrm{U} / \mathrm{mL}$ penicillin, $100 \mu \mathrm{g} / \mathrm{mL}$ streptomycin and $10 \mathrm{mM}$ HEPES. The cells were washed three times with $1 \mathrm{ml} \mathrm{RPMI}$ of containing $10 \% \mathrm{FBS}, 100 \mathrm{U} / \mathrm{mL}$ penicillin, $100 \mu \mathrm{g} / \mathrm{mL}$ streptomycin and $10 \mathrm{mM}$ HEPES. After the last centrifugation cells were resuspended in RPMI for the viability biomarker. Cell viability was observed by flow cytometry using propidium iodide (PI; Sigma-Aldrich, ON, Canada). Four $\mu \mathrm{L}$ of PI $(100 \mu \mathrm{g} / \mathrm{mL})$ were added to $200 \mu \mathrm{L}$ of each cell suspension for five min before measurement; the cells were kept on ice before the reading. PI fluorescence was analysed with a flow cytometer equipped with an argon laser excitation $(\lambda=488 \mathrm{~nm} \pm 10 \mathrm{~nm})$ (Guava Easycyte, Millipore, USA). The PI fluorescence for each well was measured in triplicate at the FL3 channel at $625 \mathrm{~nm}$ with $42 \mathrm{~nm}$ bandwidth, and 5000 events were registered.

Phagocytosis: Phagocytic activity for macrophages was measured using fluorescent latex beads following the procedure of Brousseau et al., [30]. Briefly, $1 \mathrm{ml}$ of adjusted cell concentration ( 2 million/ml) was added to 24 cell cultures coated well plate in duplicate. Cells were incubated with a ratio 100:1 of fluorescent latex beads (Polysciences, PA, USA) in order to observe the phagocytosis capacity of the cells. After an incubation period of $18 \mathrm{~h}$ at $15^{\circ} \mathrm{C}$, the cell suspensions were overlaid with $4 \mathrm{~mL}$ of PBS-g supplemented with $3 \%$ bovine serum albumin (BSA) (Sigma-Aldrich, ON, Canada). The cell suspension was centrifuged at $150 \mathrm{xg}$ for $8 \mathrm{~min}$ at $4^{\circ} \mathrm{C}$. This step permitted removal of free and loosely adhered beads at the cell surface. Cell pellets were then fixed in a solution composed of $0.5 \%$ formaldehyde and $0.2 \%$ sodium azide in a PBS solution (Sigma-Aldrich, On, Canada). Cell fluorescence was analysed by flow cytometry with an argon laser $(\lambda=488 \mathrm{~nm} \pm 10$ $\mathrm{nm}$ ) (Guava Easycyte, CA, USA). Latex bead florescence was detected for each well with the FL1 channel and a bandwidth filter of $530 \mathrm{~nm}-42$ $\mathrm{nm}$. At least 10000 events were acquired for each sample in duplicate. The immunoefficiency was operationally defined by the number of cells that were able to ingest three beads or more (M2).

Reduced thiol levels: The intracellular thiol concentration was measured by the 5-chloromethylfluorescein diacetate probe (CMFDA) (Invitrogen, Burlington, Canada) according to a method adapted from Brousseau et al. [30] and Lilius et al., [31]. Two hundred uL of leucocytes (adjusted to 2 million/ml) were added on a black 96-well plate in duplicate. After exposure for $18 \mathrm{~h}$ (as described above), the supernatant was discarded and the adherent cells were resuspended in $200 \mu \mathrm{L}$ sterile PBS-G ( $1 \mathrm{~g}$ glucose/L) and washed once during $5 \mathrm{~min}$ at $500 \mathrm{~g}$. Then the cells were resuspended and stained with CMFDA (final concentration of $5 \mu \mathrm{M}$ ) under agitation for $30 \mathrm{~min}$ at $15^{\circ} \mathrm{C}$ in the dark. After incubation plates were washed once time at $2000 \mathrm{~g}$ for $1 \mathrm{~min}$ in an incubation buffer to remove unconjugated reactant [31]. Thiol production was detected by fluorescence at $485 \mathrm{~nm}$ for excitation and $535 \mathrm{~nm}$ for emission (Bioscan, Chameleon II). The level of intracellular thiols was indicated by means of the fluorescence intensity of the stained probes

\section{Biochemical biomarkers}

Hepatic tissue damage was determined by measuring lipid peroxidation (LPO), Glutathione S-transferase (GST) and activity of cyclooxygenase (COX). LPO was determined according to the thiobarbituric acid (TBARS) methodology [32]. Thiobarbituric acid reactants were detected by fluorescence at $540 \mathrm{~nm}$ excitation and $590 \mathrm{~nm}$ emission. The data were expressed as $\mathrm{g}$ TBARS/mg proteins. Glutathione S-transferase (GST) was determined a spectrophotometric methodology using 2,4-dichloronitrobenzene as the co-substrate and reduced GSH according to the method of Gowland et al., [33]. The data were expressed as the increase in absorbance at $340 \mathrm{~nm} / \mathrm{min} /$ total proteins. 
The activity of cyclooxygenase (COX) in hepatocytes was measured by oxidation of 2,7-dichlorofluorescin with the arachidonic acid. The biochemical biomarkers was previously used by Bouchard et al.,[34] and was adapted for fish hepatocytes. Briefly, the liver was homogenised in homogenisation buffer $\mathrm{pH} 7.4(100 \mathrm{mM} \mathrm{NaCl}, 25 \mathrm{mM}$ HEPES$\mathrm{NaOH}, 0.1 \mathrm{mM}$ DTT, Aprotinin $1 \mathrm{mg} / \mathrm{ml})$ as described in Gagné [32]. One $\mathrm{ml}$ for each sample was centrifugated at $10000 \mathrm{xg}, 10 \mathrm{~min}, 4^{\circ} \mathrm{C}$. The pellet was then resuspended in $150 \mu \mathrm{L}$ of PBS where $25 \mu \mathrm{L}$ of the suspensionwas mixed with $150 \mu \mathrm{L}$ of Tris-EDTA buffer $50 \mathrm{mM}$, pH 8.0, containing $50 \mathrm{mM}$ Tris acetate $0.5 \mathrm{mM}$ EDTA, $0.1 \%$ of Tween 20,20 $\mu \mathrm{M}$ of arachidonic acid, $20 \mu \mathrm{M}$ of dichlorofluorescin diacetate and 0.1 $\mu \mathrm{g} / \mathrm{mL}$ peroxidase. The plates were read according to a kinetic from 0 to $30 \mathrm{~min}$,and fluorescence readings were taken every $5 \mathrm{~min}$ at $485 \mathrm{~nm}$ for excitation and $535 \mathrm{~nm}$ for emission (Bioscan, Chameleon II). The data were expressed as $\triangle \mathrm{RFU}$ (increase of the relative units of fluorescence)/ (min $\times$ mg proteins).

All the biomarkers were normalized with the total individual protein concentration according to Bradford methodology [35] with bovine serum albumin as the standard. Total protein concentration was measured with the absorption at $595 \mathrm{~nm}$ by a microplate reader (PowerWave, BioTek). All the biomarkers analyses were performed in triplicate.

\section{Data analysis}

Differences between the biomarkers were examined using a one way ANOVA when data normality was confirmed using ShapiroWilk normality test. Inter-group comparisons were done using the Tukey test. Differences between water types and the forms of Ag were analyzed using a two way ANOVA after confirming data normality with the Shapiro-Wilk normality test. When data were not normal, a Kruskal Wallis ANOVA was used instead and critical differences between treatments were appraised using the Mann-Whitney rank test. Significance was set at $\alpha<0.05$ in all cases.

Pearson-moment correlations were performed for studying the relation between the biomarkers responses in fish exposed to AgNPs and $\mathrm{AgNO}_{3}$ and the three types of water. Discriminant analyses were performed to examine the global response patterns of the 6 biomarkers (immunoefficiency, thiols production, COX activity, GST activity, LPO) between the contaminants and the three types of water. All the statistical analyses were conducted with STATISTICA (version 7, Statsoft Inc., 1995).

\section{Results}

\section{Nanoparticles in different types of water}

AgNPs in stock solution had a mean diameter of $19.2 \pm 0.3 \mathrm{~nm}$ (Figure 1 and Table 1) as shown by TEM image analysis, which corresponds to the size mentioned by the manufacturer. They are spherical and in monomeric form (Figure 1).

TEM image analysis revealed that these surface waters influenced the size and shape of the NPs in the different types of water (Figure 2A). In tap water, aggregated NPs took a chain and star shape appearance. The original spherical shape of AgNPs was changed in green water which suggests degradation of the AgNP (Figure 2B). In brown water, AgNPs remained as spheres of about $20 \mathrm{~nm}$ diameter. The energy dispersive spectra (EDS) graphs 1,2 and 3 confirm that all the observed nanoparticles were silver nanoparticles (Figure 2). On the EDS spectra, the presence of $\mathrm{Cu}$ was only due to TEM copper grid while the presence of gold $(\mathrm{Au})$ (spectra 1 and 3) was due to an alloy between silver and gold retrieved in water.

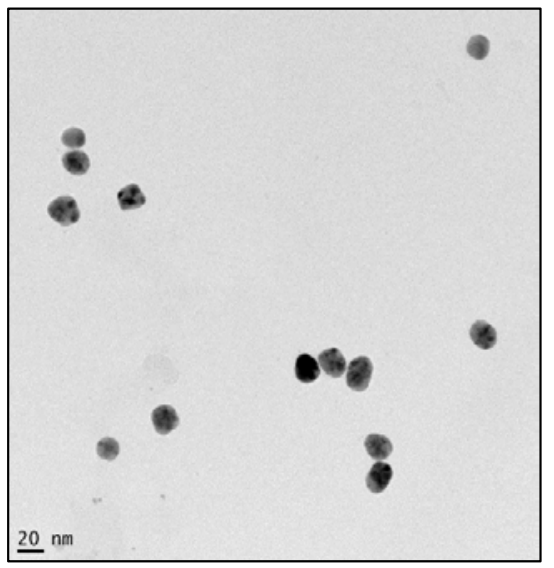

Figure 1: Transmission Electron Microscope (TEM) of AgNPs in Ted Pella stock solution. All the nanoparticles are in a monomeric form with a spherical shape.

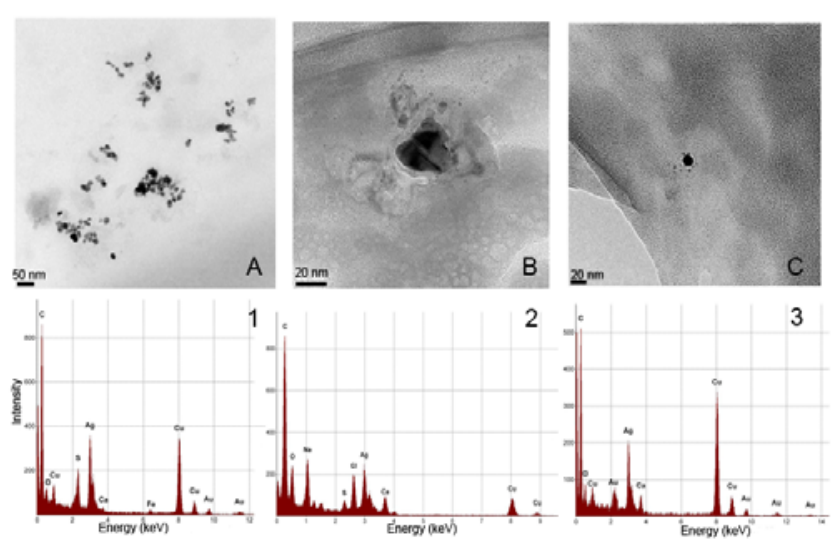

Figure 2: Silver morphology in various media and elemental composition analysis. Ag nanoparticles were prepared in (A) tap, (B) green and (C) brown waters. The EDS elemental analysis data are presented below for each treatment group and confirm that each image show silver nanoparticles.

\begin{tabular}{|c|c|c|}
\hline Samples & Mean size & Zeta potential \\
\hline stock solution & $19.2 \pm 0.3 \mathrm{~nm}$ & $-58.02 \pm 4.21 \mathrm{mV}$ \\
\hline tap & $90 \pm 3.8 \mathrm{~nm}$ & $0.00 \pm 0.00 \mathrm{mV}$ \\
\hline green & $40.1 \pm 1.2 \mathrm{~nm}$ & $-4.62 \pm 2.58 \mathrm{mV}$ \\
\hline brown & $34.6 \pm 2.1 \mathrm{~nm}$ & $-0.09 \pm 0.01 \mathrm{mV}$ \\
\hline
\end{tabular}

Table 2: Mean size and Zeta potential of AgNPs in the three types of water. These results were observed with a DLS after a filtration throughout a membrane of 0.45 um in order to eliminate large aggregates in the solution and measure the mean size of the particle.

Mean size of AgNPs measured by DLS in stock water was in agreement with the manufacturer specifications (Table 2). In the three surface waters, NPs were typically larger than $20 \mathrm{~nm}$. The largest NP sizes were observed in tap water $(90 \pm 3.8 \mathrm{~nm})$ followed in green $(40.1 \pm 1.2 \mathrm{~nm})$ and brown waters $(34.6 \pm 2.1 \mathrm{~nm})$. The mean size in waters corresponded to an aggregate of 2 to 5 individual NPs (Table 2). On the one hand, the estimated hydrodynamic size measurements were performed with DLS after a filtration on a $450 \mathrm{~nm}$ membrane to remove the large colloids. On the other hand, TEM pictures were taken without filtration steps that could explain the variation between the measured sizes. However, the DLS measures indicate the mean true 
size of monomeric nanoparticles. Same tends in size were observed with TEM and DLS results. This aggregation was confirmed with the low Zeta potentials obtained with AgNPs "dissolved" in tap and brown water (Table 2).

\section{Silver speciation}

The behavior of AgNPs and $\mathrm{AgNO}_{3}$ where determined in the 3 types of water at the start of the exposure period (Figures 3A and 3B). Regardless of the water type, a sharp decrease in silver concentration was measured for AgNPs between the total and $450 \mathrm{~nm}$, indicating that silver was preferentially aggregated in large colloids $\geq 450 \mathrm{~nm}$ (Figure $3 \mathrm{~A})$. Aggregation was higher for tap water compared to brown and green waters suggesting that AgNPs were found in large colloids. Small aggregates were also observed at sizes < for tap (5\%), green $(2 \%)$ and brown waters $(9 \%)$. For $\mathrm{AgNO}_{3}$. a weak proportion of truly dissolved silver, i.e. $<1 \mathrm{kDa}$ fraction, was detected in tap, green and brown waters at $\mathrm{Ag}$ concentrations of $0.06,0.02$ and $0.015 \mu \mathrm{g} / \mathrm{L}$, respectively. These results confirmed that $\mathrm{AgNO}_{3}$ released more $\mathrm{Ag}^{+}$in tap water than in green and in brown waters which represented respectively $0.2,0.07$, and $0.04 \%$ of the initial added $\mathrm{AgNO}_{3}$ concentration. With $\mathrm{AgNO}_{3}, \mathrm{Ag}$ was mainly retrieved at sizes $<100 \mathrm{~nm}(\operatorname{tap}=68 \%$, green $=55 \%$ and brown water $=55 \%$ measured in the $100 \mathrm{~nm}$ fraction filtrate) (Figure 3B). Small aggregates were also measured at sizes $<50 \mathrm{~nm}$ : tap $=18 \%$ of the initial unfiltrated concentration, green $=15 \%$ and brown water $=29 \%$ ) indicating that $\mathrm{AgNO}_{3}$ is associated to colloids in natural water. Few $\mathrm{Ag}^{+}$were retrieved in the permeate fraction $(1 \mathrm{kDa})$ : tap $=0.02 \mu \mathrm{g} / \mathrm{L}$, green $=0.01 \mu \mathrm{g} / \mathrm{L}$ and brown $=0.01 \mu \mathrm{g} / \mathrm{L}$.

\section{Bioavailability of Ag}

The levels of total Ag were determined in gills and liver in trout exposed to AgNPs and $\mathrm{AgNO}_{3}$ in tap, green and brown waters (Figures $4 \mathrm{~A}$ and $4 \mathrm{~B}$ ). In gills, a significant increase in silver concentration was observed for AgNPs and $\mathrm{AgNO}_{3}$ for all three types of water (Figure 4A). Tissue levels of Ag in gills were in the order 10 times less compared to liver tissues. Ag concentrations in the gills of the fish exposed to AgNPs in tap water were significantly higher than those measured in gills of fish exposed to AgNPs in green but not in brown water. Ag concentrations in the gills of fish exposed to AgNPs in brown water were no different from those in the green and tap waters which suggest

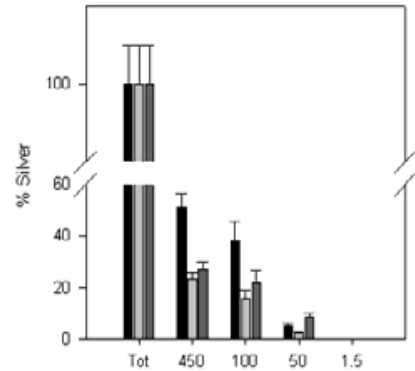

A Filtration membrane (nm)

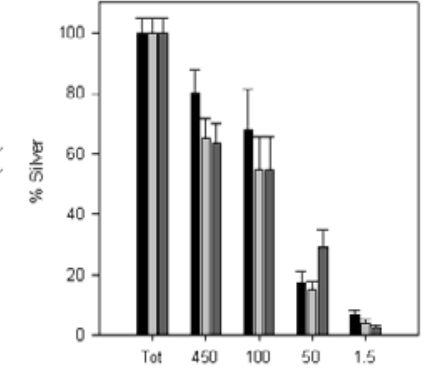

B Filtration membrane (nm)

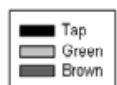

Figure 3: Silver size distribution in tap water, green water, and brown water with: A) AgNPs and $\mathrm{B}) \mathrm{AgNO}_{3}$ treatment. The initial silver concentrations measured in water were: tap water $=25 \mathrm{ug} / \mathrm{L}$, green water $=28 \mathrm{ug} / \mathrm{L}$, brown water $=34 \mathrm{ug} / \mathrm{L}$. The silver concentrations measured were performed in the filtrate fractions. Dissolved silver was found in the $1 \mathrm{kDa}$ membrane permeate fraction $(1.5 \mathrm{~nm})$. A higher silver concentration was measured with $\mathrm{AgNO}_{3}$ in 100 and $50 \mathrm{~nm}$ fractions rather than with AgNPs. No dissolved silver was observed in the 1.5 $\mathrm{nm}$ fraction with AgNPs instead of $\mathrm{AgNO}_{3}$.
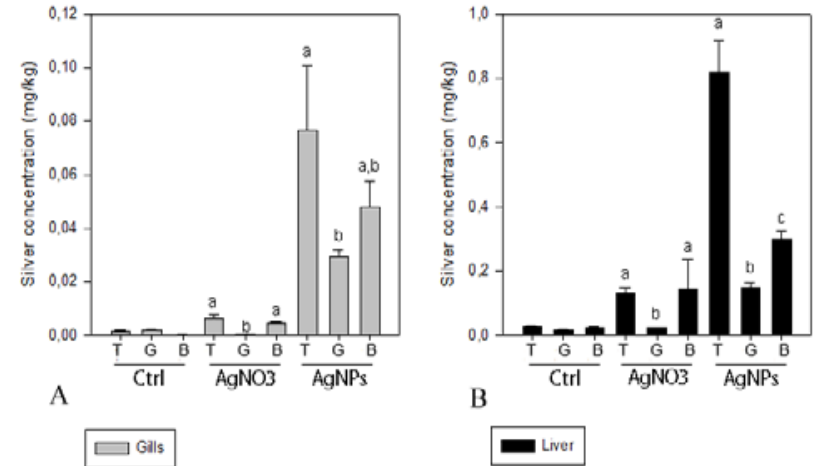

Figure 4: Silver concentrations ( $\mathrm{mg} / \mathrm{kg}$ wet wt.) in gills $(A)$ and liver $(B)$ of rainbow trout exposed to AgNPs and $\mathrm{AgNO}_{3}$. $\mathrm{T}=\mathrm{Tap}$ water, $\mathrm{G}=\mathrm{Green}$ water, $\mathrm{B}=\mathrm{Brown}$ water, $\mathrm{Ctrl}=$ control, $\mathrm{AgNO}_{3}=$ dissolved silver and $\mathrm{AgNPs}=$ silver nanoparticles. Letters represent significant differences between silver concentrations among the three types of water for each treatment. "a" is significantly different from "b" and from "c". Significant silver bioaccumulations were observed with both silver forms between exposed and control treatments $(p<0.05)$ for the three types of waters except with $\mathrm{AgNO}_{3}$ in liver with green water. Error bars correspond to standard error. ${ }^{*} p<0.05$.

surface water properties had little effects on AgNPs uptake in gills. However, gill $\mathrm{Ag}$ concentrations from fish exposed to $\mathrm{AgNO}_{3}$ and AgNPs in tap and brown waters were significantly higher from the concentrations measured in the gills of the fish exposed in green waters. Gills Ag concentrations in fish exposed to $\mathrm{AgNO}_{3}$ in brown water were not different from those in tap water. Water types could be ranked according to the silver bioaccumulation in the gills in decreasing order: tap $\sim$ brown $>$ green water.

Significant increases in silver concentration in fish liver were observed for both $\mathrm{AgNPs}$ and $\mathrm{AgNO}_{3}$ in tap and brown waters (Figure $4 \mathrm{~B})$. In green water, a significant increase in silver concentration was observed in liver for AgNPs but not with $\mathrm{AgNO}_{3}$. Silver concentrations in the livers of the fish exposed to AgNPs in tap water were significantly higher from those measured in green and brown waters in decreasing order: tap $\sim$ brown $>$ green water. The silver concentrations in the livers of the fish exposed to $\mathrm{AgNO}_{3}$ in green water were significantly lower from those measured in both tap and brown waters which is similar the bioaccumulation values in the gills.

\section{Immunocompetence evaluation}

Viability: No significant difference was observed for leucocytes viability for $\mathrm{AgNPs}$ and $\mathrm{AgNO}_{3}$ in tap water. In green water, a significant increase was observed for macrophage between control and $1 \mu \mathrm{g} / \mathrm{L}$ of $\mathrm{AgNO}_{3}(\mathrm{p}<0.05)$ (data not shown). In brown water, a significant increase for macrophage viability was observed between control and $50 \mu \mathrm{g} / \mathrm{L}$ of AgNPs $(\mathrm{p}<0.05)$ (data not shown). Moreover, the viability of the cells for each treatment was kept above $80 \%$ after $18 \mathrm{~h}$ of exposure, indicating not harmful effect.

Phagocytosis: Phagocytosis efficiency was determined in fish leucocytes exposed to the silver in the three types of water (Figure 5).

In tap water, $\mathrm{AgNO}_{3}$ reduced phagocytosis activity by 0.7 fold of the control while AgNPs did not show any effects. In green water, phagocytosis was only increased by $\mathrm{AgNO}_{3}$. In brown water, phagocytosis efficiency was increased by both forms of Ag reaching 1.9 times of the control Hence, $\mathrm{AgNO}_{3}$ effects could be drastically changed by the surface water properties. Indeed, $\mathrm{AgNO}_{3}$ was able to reduce 
Citation: Bruneau A, Turcotte P, Pilote M, Gagné F, Gagnon C (2015) Fate and Immunotoxic Effects of Silver Nanoparticles on Rainbow Trout in Natural Waters. J Nanomed Nanotechnol 6: 290. doi:10.4172/2157-7439.1000290

phagocytosis in tap water while it was increased in brown water. This merits a closer analysis of surface water modulation in fish immune responses.

In the absence of silver, phagocytosis efficiency was significantly decreased between control tap water and either green or brown water; it was reduced by 0.67 and 0.57 fold of control tap water for green and brown surface water respectively. These observations could be explained by the fact that green and brown waters were not filtered before the exposure. In the presence of AgNPs, phagocytosis efficiency was significantly decreased in brown and green waters compared to AgNPs in tap water (Figure 5). In fish exposed to $\mathrm{AgNO}_{3}$, phagocytosis efficiency was significantly higher in both green and brown waters compared to $\mathrm{AgNO}_{3}$ in tap water. However, the increase in phagocytosis reached control values (tap water) suggesting that the observed responses were close to the normal range of responses.

A two-way ANOVA revealed that water have a significant effect on immune response $(\mathrm{F}=9.78, \mathrm{p}<0.0001)$ and also the silver form $(\mathrm{F}=3.554$, $\mathrm{p}<0.05)$. A significant interaction between water and silver form was observed $(\mathrm{F}=19.79, \mathrm{p}<0.0001)$.

Oxidative stress (thiols production): A significant increase in the production of reduced thiols was observed between the control and $\mathrm{AgNO}_{3}$ for the tap water (Figure 6). Another significant increase in the production of reduced thiols was observed between the control and AgNPs for brown water suggesting the potential toxicity of the AgNPs. No change was observed in the production of reduced thiols for green water, confirming that this type of water does not induce oxidative stress.

In absence of silver, basal thiols production in tap water was higher but not significantly different from those with either green and brown waters (Figure 6). In the presence of AgNPs, thiols production in green water was significantly reduced by 0.39 fold of control tap water (Figure 6). The thiols production in tap water was not different from those in brown water (Figure 6). For fish exposed to $\mathrm{AgNO}_{3}$, thiols production
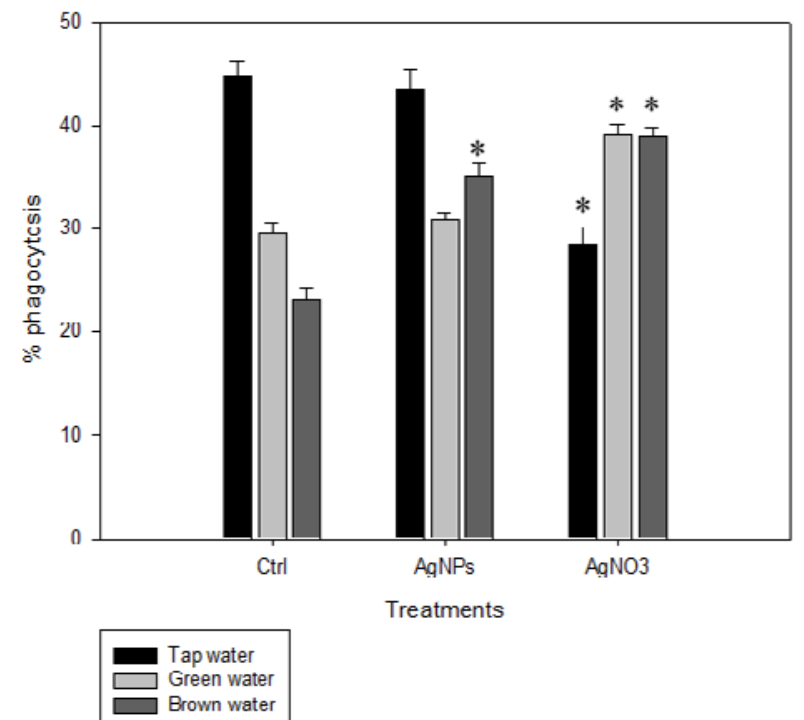

Figure 5: Immunoefficiency (phagocytosis of 3 beads and more) of rainbow trout macrophage in each types of water A) tap water, B) green water and C) brown water. Error bars correspond to standard error. ${ }^{*} p<0.05$.

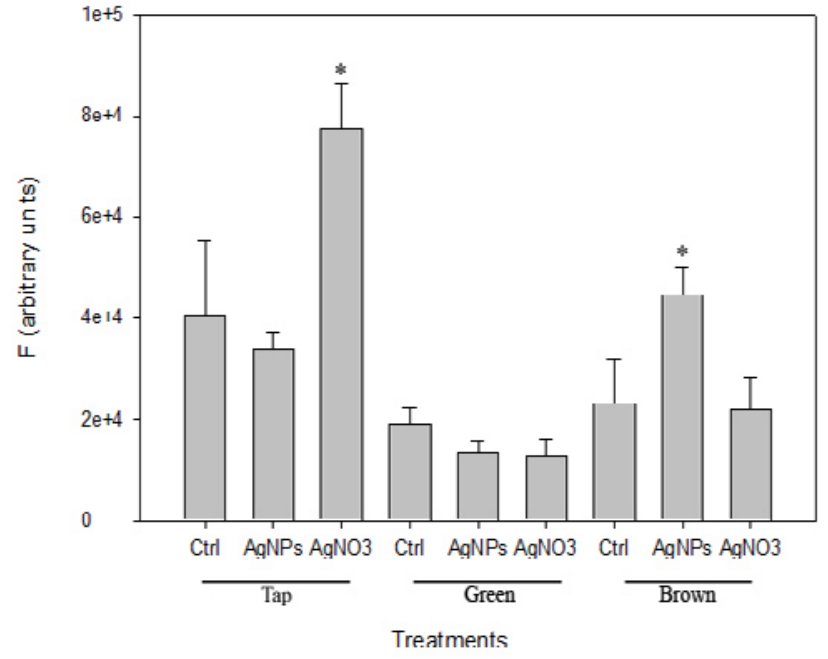

Figure 6: Thiols production of rainbow trout's macrophages in 3 types of water. Error bars correspond to standard error. ${ }^{*} \mathrm{p}<0.05$.
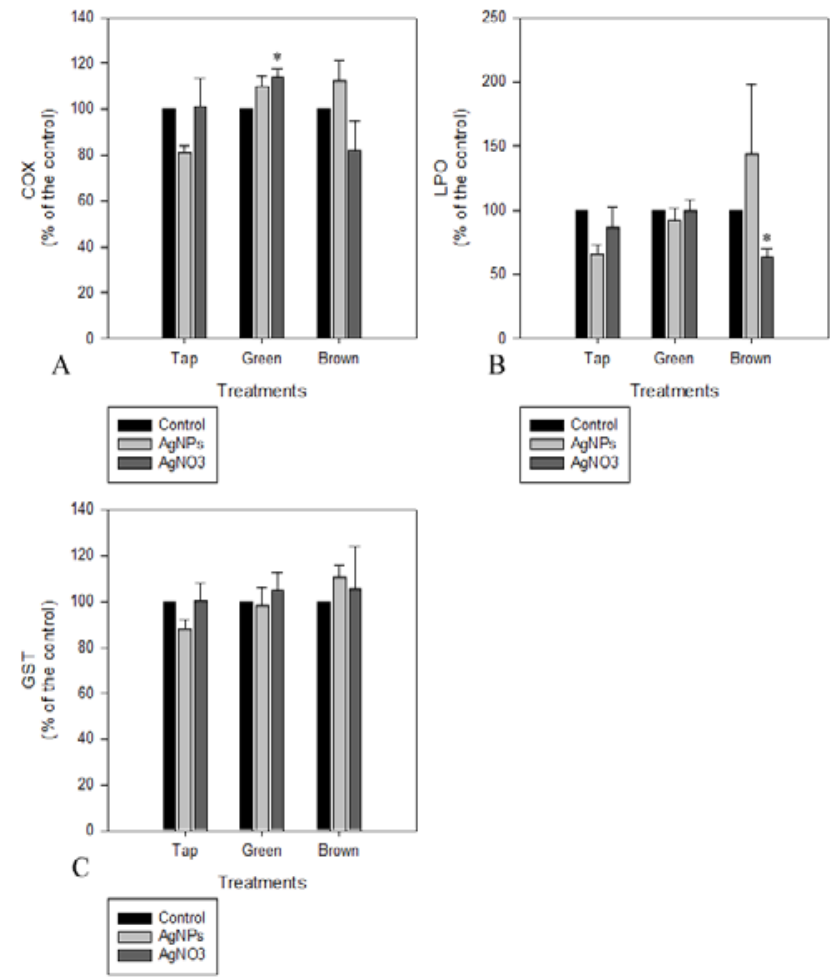

Figure 7: Biochemical biomarkers of fish hepatocytes exposed to different types of water and contaminants. A) Cyclooxygenase activity (COX), B) Lipid peroxidation (LPO), C) Glutathione-S-Transferase (GST). Results are presented as a percentage of the control, where histogram represents mean \pm standard error. Stars indicate differences between exposed vs non exposed treatments for each type of water. Only significant differences were indicated.

was significantly higher in tap water compared to $\mathrm{AgNO}_{3}$ in both green and brown waters.

The two-way ANOVA revealed that water have a much stronger 
effect on the immune response $(\mathrm{F}=37.43, \mathrm{p}<0.0001)$ than the form of $\mathrm{Ag}(\mathrm{F}=5.86, \mathrm{p}<0.05)$. Moreover, a significant interaction between water and silver form was observed $(\mathrm{F}=13.2, \mathrm{p}<0.001)$, indicating that $\mathrm{Ag}^{+}$ have more effect in tap water than in the two other water types. AgNPs induced more effect to fish in brown water than in green water. This suggests that brown water characteristics favor the expression of AgNPs while green water influences more strongly dissolved Ag effects.

\section{Hepatic biomarkers}

Inflammation responses were followed by COX activity and LPO levels and GST (Figure 7A-7C). A significant increase in COX activity was observed between $\mathrm{AgNO}_{3}$ and control samples in green water (Figure 7A). A significant decrease was observed in LPO for brown water between the control and $\mathrm{AgNO}_{3}$ (Figure 7B). No significant difference in GST activity among the waters was observed for both forms of Ag compared to the control ( $\mathrm{p}>0.05$ ) (Figure 7C).

In absence of silver, COX activity in tap water was significantly higher than COX activity in green and brown waters. COX activity was significantly higher in green than in brown water (data not shown). These results were also observed in the presence of AgNPs and $\mathrm{AgNO}_{3}$ indicating that water parameters have an influence whatever the treatments. LPO was significantly higher in brown water compared to LPO either in tap and green waters (Figure 7B). No significant difference in GST activity among the waters was observed for all the treatments $(\mathrm{p}>0.05)$ (Figure $7 \mathrm{C})$.

A two-way ANOVA indicate that the type of water have an effect on the silver form $(\mathrm{F}=164, \mathrm{p}<0.001)$. Brown water induced more inflammation than green water and this trend was observed for AgNPs.

Correlation matrix revealed that immunoefficiency was significantly correlated with $\operatorname{COX}(\mathrm{r}=0.33 ; \mathrm{p}<0.05)$ confirming the correlation between the increase of immune system response and the inflammation (Table 3). Significant correlation was also observed between COX and LPO ( $\mathrm{r}=-0.54 ; \mathrm{p}<0.05)$ and between COX and GST $(\mathrm{r}=0.42 ; \mathrm{p}<0.05)$. These results suggest an inflammatory pathway that was not associated with oxidative degradation of lipids.

Discriminant function analysis (DA) was performed on six different biomarkers (Phagocytosis efficiency, thiols production, COX, LPO and GST and silver bioaccumulation in liver and in gills) to determine the effects of both silver form and the type of water. The main biomarkers were identified on $\mathrm{X}$ and Y-axis. DA showed no association between the types of water confirming that water parameters have an influence on the fate of silver forms and their biological effects. Figure 8 revealed that the difference between tap and either green or brown waters was mostly explained by COX activity. The difference between green water and either tap or brown waters were explained by LPO (Figure 8). COX and LPO explain $100 \%$ of difference between the results (treatments and water effects).

\begin{tabular}{|l|l|l|l|l|l|l|l|}
\hline & Efficiency & Thiols & COX & LPO & GST & Bio liver & Bio gills \\
\hline Efficiency & 1 & & & & & & \\
\hline Thiols & 0.02 & 1 & & & & & \\
\hline COX & $0.33^{*}$ & 0.21 & 1 & & & & \\
\hline LPO & -0.26 & 0.19 & $-0.54^{*}$ & 1 & & & \\
\hline GST & 0.29 & 0.11 & $0.42^{*}$ & -0.11 & 1 & & \\
\hline Bio liver & -0.07 & 0.11 & 0.27 & -0.19 & 0.15 & 1 & \\
\hline Bio gills & 0.24 & 0.12 & 0.06 & 0.07 & 0.02 & 0.16 & 1 \\
\hline
\end{tabular}

Table 3: Correlation matrix between biomarkers for both silver treatments and the type of water. Efficiency=immunoefficiency, thiols=reduced thiols production, COX=cyclooxygenase activity, GST=Glutathione-S-transferase, LPO=Lipid peroxidation, Bio liver=silver bioaccumulation in the fish liver, Bio gills=silver bioaccumulation in the fish gills. * indicated significant results $(p<0.05)$.

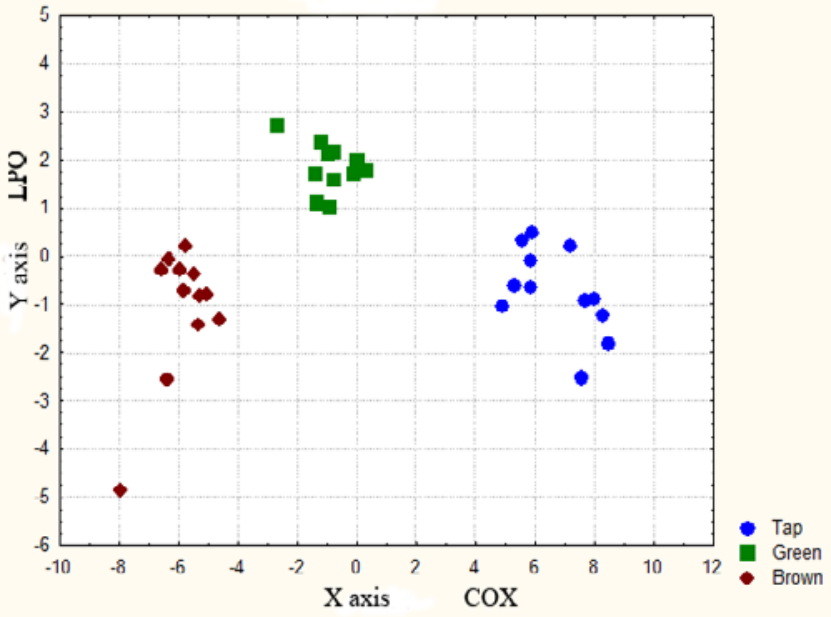

Figure 8: Discriminant analysis of the three types of water according to biochemical biomarkers responses. No association between the types of water was observed confirming that water parameters have an influence on the fate of silver forms and their biological effects. The main biomarkers were identified on $\mathrm{X}$ and $\mathrm{Y}$-axis.

\section{Discussion}

The study focused on the influence of water types on the size distribution of $\mathrm{Ag}$ from $\mathrm{AgNO}_{3}$ and AgNPs, bioavailability and resulting toxicity. Chemical results indicated that overall the AgNPs are found as large aggregate $(>100 \mathrm{~nm})$ in the three types of media. In green and tap waters, AgNPs were rather retrieved as much larger aggregates (2-5 nanoparticles i.e. $>20 \mathrm{~nm})$ than in brown water (monomeric form). The aggregation was less severe for organic-rich brown waters: $9 \%$ percent of silver from AgNPs were measured in the $50 \mathrm{~nm}$ fraction in brown water compared to $2 \%$ in green water in the same fraction. This observation was in agreement with the AgNP mean true diameter sizes measured with DLS in the three waters ( 90 $\mathrm{nm}, 40 \mathrm{~nm}$ and $34 \mathrm{~nm}$ for tap, green, and brown waters respectively). This finding confirms the observation of Gagne et al. [9], who indicated that AgNPs spontaneously form aggregates in aquarium water during natural conditions exposure. This aggregation could be due to the organic matter composed mainly by fluvic and humic acids [36,37]. The humic substances are well-known to react with metals and influence their distribution, compartmentalization and mobility in aquatic systems [38,39]. In our study, the Ca concentration in tap and green waters were higher than those in brown water tap $=29 \mathrm{mg} / \mathrm{L}$, green $=18$ $\mathrm{mg} / \mathrm{L}$ and brown $=8 \mathrm{mg} / \mathrm{L}$ ) and could partly induced the aggregation of the AgNPs [14].

The zeta potential as the measure of the surface charge of a charged particle could indicate the nanoparticle bioavailability. In our study, the high zeta potential of the stock solution suggests that the AgNPs were in monomeric form. The zeta potential of AgNPs was significantly decreased in all the studied aqueous media. On one hand, the high conductivity and alkalinity of green water would favor charge cancelation at the surface of the nanoparticle and favor aggregation. On the other hand, the presence of organic matter in brown water should stabilize the nanoparticle form without charge cancelation at the particle surface as observed by Giasuddin et al., [40] who demonstrated that humic substances sorbs to zero-valent iron NPs $[14,40]$. In tap 
water the absence of NOM, high conductivity and the alkaline $\mathrm{pH}$ favor AgNPs aggregation, which was corroborated by the appearance of chain-like structures.

Because of the increasingly use of AgNP, current research studies focus on the absorption process of silver (AgNPs and $\mathrm{Ag}^{+}$) during exposure to contaminants. The silver concentration in liver was higher than those in gills for the three types of water and both silver forms. Increase in Ag accumulated in the liver for both forms suggests that the liver is a key organ for Ag accumulation [28] even when $\mathrm{Ag}$ is in a nanoparticulate form. However, we were not able to determine the form of $\mathrm{Ag}$ in the gills and liver in the present study. The Ag accumulation in gills and liver was less important in green water than in tissues with the two other waters. No significant $\mathrm{Ag}$ accumulation in gills with $\mathrm{AgNO}_{3}$ was observed confirming that the parameters of green water decrease the silver bioavailability for the fish. We supposed that the low bioavailability of AgNPs in small colloids $(<50 \mathrm{~nm})$ reduced their bioaccumulation in gills. Thus, speciation of the two Ag forms in green water plays a major role in their accumulation.Based on the bioaccumulation data, the morphological modifications of AgNPs in tap water led to high bioavailability in liver and less so in the gills. Tap water was the media that lead to stronger increase in Ag for AgNPs and $\mathrm{AgNO}_{3}$ than brown and green water. The bioavailability of $\mathrm{Ag}^{+}$from $\mathrm{AgNO}_{3}$ in tap water (1.5 $\mathrm{nm}$ fraction) increases the absorption in fish tissues, induces silver bioaccumulation in gills and bioconcentration in liver. The absence of the $\mathrm{Ag}^{+}$from AgNPs in tap water suggests that AgNPs were absorbed as nanoparticles. Scown et al., [7] demonstrated that both small silver nanoparticles $(10 \mathrm{~nm})$ and silver bulk particles accumulated in gills and liver; the authors suggested a transport of AgNPs through the epithelial barriers (gut, skin and gills) and blood. The difference in silver accumulation between gills and liver suggest the implication of other uptake route like the gut $[7,26]$. According to Scown et al., [7], the high concentration of silver observed in fish liver with tap water may be the consequence of the fish feeding on AgNP aggregates which precipitate at the bottom of the exposure tank.

In this study, immunological effects of AgNPs and $\mathrm{AgNO}_{3}$ were evaluated in pronephros. Phagocytosis stimulations with both silver forms were observed in green and brown waters indicating that silver is associated to small colloids (either adsorbed to the organic matter or present in AgNPs of similar size range) leading to immunostimulation. In our case, the effects of $\mathrm{Ag}^{+}$and monomeric AgNPs were not discernable. This was also observed in a previous study where the effects of ionic Ag and AgNPs were not observable at the immunity level [27]. Our results showed that $\mathrm{AgNO}_{3}$ induces immunostimulation in green and brown waters, whereas animmunosuppression in tap water is observed. We supposed that the immune response follow an hormetic model [41]. This effect might be induced by residual $\mathrm{Ag}^{+}$in AgNPs suspension [42]. In the case of brown water, leucocytes were stimulated by both $\mathrm{AgNO}_{3}$ and AgNPs, whereas for tap water $\mathrm{AgNO}_{3}$ caused injuries to leucocytes.

Phagocytosis is followed by a respiratory-burst to allow complete destruction of ingested particles [43] and an induction of endogenous antioxidants, such as thiols, in order to avoid the harmful effects of the contaminant. In presence of AgNPs, reduced thiols were only increased for fish in brown water; we could expect that long exposure of AgNPs in brown water could increase their toxic effects. Previously, Moghimi et al., [44] indicated that the clearance of small NPs (in our case 30 $\mathrm{nm})$ in the blood should be slower than big NPs $(\geq 100 \mathrm{~nm})$ [23]. Interestingly, production of reduced thiols with $\mathrm{AgNO}_{3}$ in brown water was not observed indicating that the twosilver forms did not trigger the same pathway. Significant increase in reduced thiols was also observed in leucocytes when fish were exposed to $\mathrm{AgNO}_{3}$ in the tap water, suggesting that this type of water promotes the oxidative stress effects of dissolved form. With green water, no sulfhydryl groups were significantly produced to protect the body from free radical damage. These findings were in agreement with phagocytosis results confirming that the speciation of both silver forms in the green water limits their toxicity to fish.

$\mathrm{Ag}^{+}$can induce modifications of enzymatic activities in the liver [9], induced cellular lipid peroxidation [45], inflammationand reduced the total glutathione [46]. In presence of AgNPs, significant increase in LPO activity was observed in fish liver in brown water and confirm the oxyradical formation and their damages to the liver $[47,48]$. As observed in our correlation results, the increase in the COX activity was correlated to the immune stimulation, and was in agreement with the reduced thiols induction. Finally, the biological effects among the three types of waters were discriminated by inflammatory pathway (COX, LPO); brown water induced more inflammation than green water in presence of AgNPs. We demonstrated that water parameters have a much stronger effect on the biochemical effects than the silver forms.

The biochemical results indicated that the environment is a major factor that influenced the toxicity of both silver forms, and this finding can partly be explained by the fate of in water. In a relatively short time (between 0h and 96h) the level of Ag from AgNPs in the three types of water was decreased $(-46 \%,-44 \%$ and $-28 \%$ for tap, green and brown water respectively). The decrease of $\mathrm{Ag}$ concentration between the beginning and the end of the exposure period could be explained by silver assimilation by the fish or its aggregation. In our results, silver concentration of AgNPs in brown water was less decreased compared to the other waters. The chemical parameters of the brown water (high TOC, low $\mathrm{pH}$, low calcium concentration) increase the mobility and the bioavailability of AgNPs confirming that the fate of the NPs is linked to water chemistry. Silver concentrations in water from $\mathrm{AgNO}_{3}$ were decreased in $<100 \mathrm{~nm}$ fraction in the three types of water: $-32 \%$ for tap, $-45 \%$ for green and brown waters. Dissolved silver is also more present at the small colloidal fraction in brown water $(29 \%)$ than with the two other waters (18\% and $15 \%$ in tap and green water respectively) in the $<50 \mathrm{~nm}$ fraction. This finding confirms that $\mathrm{Ag}^{+}$is more available as small colloids than AgNPs. In the truly dissolved fraction $(1.5 \mathrm{~nm})$, a small amount (3-9\%) of silver from $\mathrm{AgNO}_{3}$ is bioavailable, and tap water is most effective to promote the bioavailability of dissolved $\mathrm{Ag}$ for the organism. The influence of a combination of water parameters, such as: NOM, conductivity and $\mathrm{pH}$ should be evaluated with respect to environmental nanoparticle exposure.

\section{Conclusion}

This study confirms that the type of surface water has an influence on the bioavailability and the toxicity of $\mathrm{AgNPs}$ and $\mathrm{AgNO}_{3}$. Overall the AgNPs are found as large aggregate $(>100 \mathrm{~nm})$ in the three types of media. In green and tap waters, AgNPs were rather retrieved as much larger aggregates $(2-5$ nanoparticles i.e. $>20 \mathrm{~nm}$ ) than in brown water (monomeric form). Silver from AgNPs was preferentially bioconcentrated in the liver whatever the type of water. Brown water with high TOC values $(7 \mathrm{mg} / \mathrm{L})$ and acid $\mathrm{pH}$ allows AgNPs to remain as stable monomeric form that is bioavailable for fish tissues. After absorption, the AgNPs induces light immunostimulation and oxidative stress. The alkalinity, the high conductivity and the $\mathrm{Ca}^{2+}$ concentration 
of the green water induce morphological transformations of the monomeric AgNPs but neither immune nor hepatic damage was observed. The low concentrations of the NOM, the high conductivity and the alkalinity of the tap water, promote the aggregation of the particles and their deformation. Silver was mainly bioaccumulated in liver but neither immune nor hepatic disturbance were observed.

Brown water increases the $\mathrm{Ag}^{+}$accessibility in media, promoting their availability for fish tissues, and immunostimulation without oxidative stress was observed. In green water, silver was only bioaccumulated in gills when exposed to $\mathrm{AgNO}_{3}$. $\mathrm{AgNO}_{3}$ triggers leucocytes stimulation and hepatic pro-inflammatory response (COX). The bioavailability of colloidal $\mathrm{AgNO}_{3}$ in tap water induced high accumulation in the liver without hepatic injury. Immune perturbations were observed as immunosuppression and oxidative stress in pronephros.

In case of AgNP release in the environment, water similar to brown water could increase the dispersion of AgNPs in monomeric form or small aggregates, promoting their long term bioavailability and their absorption as NP. Further research on nanotoxicity should consider exposure conditions and AgNP fate in water media for risk assessments.

\section{Acknowledgement}

We would like to thank Jean-Philippe Masse from the $\mathrm{CM}^{2}$ (Centre de Caractérisation Microscopique des Matériaux, École Polytechnique de Montréal, Montréal, QC) for suppling the transmission electronic microscopyWe thank Gwenaël Chamoulaud from NanoQam (Université du Québec à Montréal, Montréal, QC) for the dynamic light scattering analyses. We thank Michel Arseneau for water sampling. We are grateful to Mélanie Verdier for her laboratory work on biochemical biomarkers. Thanks go to Dr. Richard Cooper for the English writing advice. This work was supported by Environment Canada's Chemicals Management Plan funds.

\section{References}

1. Lok CN, Ho CM, Chen R, He QY, Yu WY, et al. (2007) Silver nanoparticles: partial oxidation and antibacterial activities. J Bio Inorg Chem 12: 527-534.

2. Sharma VK, Yngard RA, Lin Y (2009) Silver nanoparticles: green synthesis and their antimicrobial activities. Adv Colloid Interface Sci 145: 83-96.

3. Jones SA, Bowler PG, Walker M, Parsons D (2004) Controlling wound bioburden with a novel silver-containing Hydrofiber dressing. Wound Repair Regen 12: 288-294.

4. Asharani PV, Lian Wu Y, Gong Z, Valiyaveettil S (2008) Toxicity of silver nanoparticles in zebrafish models. Nanotechnology 19: 255102.

5. Farkas J, Christian P, Urrea JA, Roos N, Hassellöv M, et al. (2010) Effects of silver and gold nanoparticles on rainbow trout (Oncorhynchusmykiss) hepatocytes. Aquat Toxicol 96: 44-52.

6. Massarsky A, Abraham R, Nguyen KC, Rippstein P, Tayabali AF, et al. (2014) Nanosilver cytotoxicity in rainbow trout (Oncorhynchus mykiss) erythrocytes and hepatocytes. Comp Biochem Physiol-C Toxicol Pharmacol 159: 10-21.

7. Scown TM, Santos EM, Johnston BD, Gaiser B, Baalousha M, et al. (2010) Effects of aqueous exposure to silver nanoparticles of different sizes in rainbow trout. Toxicol Sci 115: 521-534.

8. Griffitt RJ, Lavelle CM, Kane AS, Denslow ND, Barber DS (2013) Chronicnanoparticulate silver exposure results in tissue accumulation and transcriptomic changes in zebrafish. Aquat Toxicol 130-131: 192-200.

9. Gagné F, André C, Skirrow R, Gélinas M, Auclair J, et al. (2012) Toxicity of silver nanoparticles to rainbow trout: a toxicogenomic approach. Chemosphere 89: 615-622.

10. Liu J, Wang Z, Liu FD, Kane AB, Hurt RH (2012) Chemical transformations of nanosilver in biological environments. ACS Nano 6: 9887-9899.

11. Baalousha M, Manciulea A, Cumberland S, Kendall K, Lead JR (2008)
Aggregation and surface properties of iron oxide nanoparticles: Influence of $\mathrm{pH}$ and natural organic matter. Environ Toxicol Chem 27: 1875-1882.

12. Grassian VH, Hamers RJ (2011) Nanomaterials and the Environment: The Chemistry and Materials Perspective: Arlington.

13. Chowdhury I, Cwiertny DM, Walker SL (2012) Combined factors influencing the aggregation and deposition of nano-TiO2 in the presence of humic acid and bacteria. Environ Sci Technol 46: 6968-6976.

14. Christian P, Von der Kammer F, Baalousha M, Hofmann T (2008) Nanoparticles: structure, properties, preparation and behaviour in environmental media. Ecotoxicology 17: 326-343.

15. Kittler S, Greulich C, Diendorf J, Köller M, Epple M (2010) Toxicity of silver Nanoparticles increases during storage because of slow dissolution under release of silver ions. Chem Mater 22: 4548-4554.

16. Yu SJ, Yin YG, Liu JF (2013) Silver nanoparticles in the environment. Environ Sci Process Impacts 15: 78-92.

17. Luoma SN (2008) Silver nanotechnologies and the environment: old problems or new challenges.

18. Agency for Toxic Substances and Disease Registry ATSDR, Toxicological profile for silver., P.H.S. Health and Human Services, Agency for Toxic Substances and Disease Registry, Editor. 1990: Atlanta, GA, US.

19. World Health Organization (2002) World Health Organization WHO, Silver and silver compounds: Environmental aspects, Geneva.

20. Wijnhoven WP, Peijnenburg WJGM, Herberts CA, Hagens WI, Oomen AG, et al. (2009) Nano-silver-a review of available data and knowledge gaps in human and environmental risk assessment. Nanotoxicology 3: 109-138.

21. Handy RD, Henry TB, Scown TM, Johnston BD, Tyler CR (2008) Manufactured nanoparticles: their uptake and effects on fish--a mechanistic analysis. Ecotoxicology 17: 396-409.

22. Moore MN (2006) Do nanoparticles present ecotoxicological risks for the health of the aquatic environment? Environ Int 32: 967-976.

23. Caron WP, Rawal S, Song G (2013) Bidirectional interaction between nanoparticles and cells of the mononuclear phagocytic system.

24. Liu J, Hurt RH (2010) Ion release kinetics and particle persistence in aqueous nano-silver colloids. Environ Sci Technol 44: 2169-2175.

25. Park EJ, Bae E, Yi J, Kim Y, Choi K, et al. (2010) Repeated-dose toxicity and inflammatory responses in mice by oral administration of silver nanoparticles. Environ Toxicol Pharmacol 30: 162-168.

26. Griffitt RJ, Hyndman K, Denslow ND, Barber DS (2009) Comparison of molecular and histological changes in zebrafish gills exposed to metallic nanoparticles. Toxicol Sci 107: 404-415.

27. Gagné F, Auclair J, Fortier M, Bruneau A, Fournier M, et al. (2013) Bioavailability and immunotoxicity of silver nanoparticles to the freshwater mussel Elliptiocomplanata. J Toxicol Environ Health A 76: 767-777.

28. Hogstrand C, Galvez F, Wood CM (1996) Toxicity, silver accumulation and metallothionein induction in freshwater rainbow trout during exposure to different silver salts. Environ Toxicol Chem 15: 1102-1108.

29. Bruneau A, Fortier M, Gagne F, Gagnon C, Turcotte P, et al. (2013) Size distribution effects of cadmium tellurium quantum dots (CdS/CdTe) immunotoxicity on aquatic organisms. Environ Sci Process Impacts 15: 596-607.

30. Brousseau P, Payette P, Tryphonas H, Blakley B, Boermans H, et al., (1998) Manual of Immunological Methods. CRC Press, Boca Raton, Florida, USA.

31. Lilius H, Hästbacka T, Isomaa B (1996) A combination of fluorescent probes for evaluation of cytotoxicity and toxic mechanisms in isolated rainbow trout hepatocytes. Toxicol In vitro 10: 341-348.

32. F. Gagné 2014 Biochemical Ecotoxicology, 1st Edition, Principles and Methods. 1 st ed, ed. A. press.

33. Gowland BTG, McIntosh AD, Davies IM, Moffat CF, Webster L (2002) Implications from a field study regarding the relationship between polycyclic aromatic hydrocarbons and glutathione S-transferase activity in mussels. Mar Environ Res 54: 231-235.

34. Bouchard B, Gagné F, Fortier M, Fournier M (2009) An in-situ study of the impacts of urban wastewater on the immune and reproductive systems of 
Citation: Bruneau A, Turcotte P, Pilote M, Gagné F, Gagnon C (2015) Fate and Immunotoxic Effects of Silver Nanoparticles on Rainbow Trout in Natural Waters. J Nanomed Nanotechnol 6: 290. doi:10.4172/2157-7439.1000290

the freshwater mussel Elliptio complanata. Comp Biochem Physiol-C Toxicol Pharmacol 150: 132-140.

35. Bradford MM (1976) A sensitive method for total protein determination using the principle of protein-dye binding. Anal Biochem 72: 249-251.

36. Cumberland SA, Lead JR (2009) Particle size distributions of silver nanoparticles at environmentally relevant conditions. J Chromatogr A 1216: 9099-9105.

37. Ghabbour EA, Davies G (2001) Humic Substances: Structures, Models and Functions: Royal Society of Chemistry.

38. Ephraim JH, and B. Allard B (1997) Metal ion binding by humic substances (Chapter IV) In Modelling in aquatic chemistry. OECD Publishing, Puigdomenech, France.

39. Duval JF (2009) Metal speciation dynamics in soft colloidal ligand suspensions. Electrostatic and site distribution aspects. J Phys Chem A 113: 2275-2293.

40. Giasuddin AB, Kanel SR, Choi H (2007) Adsorption of humic acid onto nanoscalezerovalent iron and its effect on arsenic removal. Environ Sci Technol 41: 2022-2027

41. Calabrese EJ (2004) Hormesis: a revolution in toxicology, risk assessment and medicine. EMBO Rep 5 Spec No: S37-40.
42. Xiu ZM, Zhang QB, Puppala HL, Colvin VL, Alvarez PJ (2012) Negligible particle-specific antibacterial activity of silver nanoparticles. Nano Lett 12 : 4271-4275.

43. Dobrovolskaia MA, McNeil SE (2013) Handbook of Immunological Properties of Engineered Nanomaterials Frontiers in Nanobiomedical Research.

44. Moghimi SM, Szebeni J (2003) Stealth liposomes and long circulating nanoparticles: critical issues in pharmacokinetics, opsonization and proteinbinding properties. Prog Lipid Res 42: 463-478.

45. Choi JE, Kim S, Ahn JH, Youn P, Kang JS, et al. (2010) Induction of oxidative stress and apoptosis by silver nanoparticles in the liver of adult zebrafish. Aquat Toxicol 100: 151-159.

46. Chae YJ, Pham CH, Lee J, Bae E, Yi J, et al. (2009) Evaluation of the toxic impact of silver nanoparticles on Japanese medaka (Oryziaslatipes). Aquat Toxicol 94: 320-327.

47. Stohs SJ, Bagchi D (1995) Oxidative mechanisms in the toxicity of metal ions Free Radic Biol Med 18: 321-336.

48. Viarengo A, Canesi L, Pertica M, Poli G, Moore MN, et al. (1990) Heavy metal effects on lipid peroxidation in the tissues of Mytilus galloprovincialis clam. Comp Biochem Physiol-C Toxicol Pharmacol 97: 37-42. 